\title{
Hippocampal Inactivation Disrupts Contextual Retrieval of Fear Memory after Extinction
}

\author{
Kevin A. Corcoran ${ }^{1}$ and Stephen Maren ${ }^{1,2}$ \\ ${ }^{1}$ Department of Psychology and ${ }^{2 N e u r o s c i e n c e ~ P r o g r a m, ~ U n i v e r s i t y ~ o f ~ M i c h i g a n, ~ A n n ~ A r b o r, ~ M i c h i g a n ~ 48109-1109 ~}$
}

Recent studies implicate the hippocampus in contextual memory retrieval. The present experiments explore this possibility by examining the impact of reversible inactivation of the dorsal hippocampus $(\mathrm{DH})$ on the context-specific expression of extinction. In experiment 1, rats were conditioned to fear a tone conditional stimulus (CS) and subsequently extinguished either in the same context as conditioning or in a novel context. A third group of rats underwent fear conditioning but did not receive extinction. After extinction, conditional fear to the tone CS was assessed in the conditioning context by measuring freezing. Rats extinguished in the conditioning context exhibited low levels of freezing, whereas those extinguished in a different context and those that received no extinction showed high levels of freezing. This indicates that the expression of extinction is context-specific. In experiment 2, the context-

It is a decades-old maxim in the learning and memory literature that the successful retrieval of a stored memory representation is often contingent on the similarity between the conditions present at the time of learning and those present at the time of retrieval (Spear, 1973; Tulving and Thomson, 1973). The use of contextual cues for the retrieval of memories plays an important role in memory processes ranging from declarative memory in humans (Maguire et al., 1997) to Pavlovian fear conditioning in animals (Bouton, 1993; Maren and Holt, 2000). One brain structure that has been implicated in contextual memory retrieval is the hippocampus (Hirsh, 1974; Good and Honey, 1991; Holland and Bouton, 1999). For example, we have shown recently that contextual retrieval of latent inhibition (LI) is disrupted by reversible inactivation of the dorsal hippocampus (DH) (Holt and Maren, 1999). In latent inhibition, conditional responding decreases as a result of nonreinforced presentations of the to-be-conditional stimulus [i.e., conditional stimulus (CS) preexposure] before conditioning. The expression of LI is context-specific insofar as the decrement in conditional responding only occurs if CS preexposure and retrieval testing occur in the same context (Westbrook et al., 2000). We found that inactivation of the $\mathrm{DH}$ before retrieval testing blocks the context-specific expression of LI (Holt and Maren, 1999).

\footnotetext{
Received Nov. 1, 2000; revised Dec. 13, 2000; accepted Dec. 18, 2000.

This research was supported by Grant MH57865 from the National Institute of Mental Health (S.M.). We thank Mark Bouton and Russell Frohardt for comments on an earlier version of this manuscript and Chris Kobet and Kelley Kozma for technical assistance.

Correspondence should be addressed to Stephen Maren, Department of Psychology, University of Michigan, 525 East University Avenue, Ann Arbor, MI 481091109. E-mail: maren@umich.edu.

Copyright (C) 2001 Society for Neuroscience $\quad 0270-6474 / 01 / 211720-07 \$ 15.00 / 0$
}

specific expression of extinction was disrupted by infusion of muscimol, a $\mathrm{GABA}_{\mathrm{A}}$ receptor agonist, into the $\mathrm{DH}$. Rats that received muscimol infusions into the $\mathrm{DH}$ showed little freezing to the tone CS, regardless of whether the CS had been extinguished in the testing context or another context. In experiment 3 , intrahippocampal muscimol infusions did not disrupt the expression of conditional freezing to the tone CS in rats that did not receive extinction. Thus, muscimol infusion into the $\mathrm{DH}$ produced a selective impairment in the context-specific expression of extinction. These results extend findings from other behavioral paradigms and provide additional support for a role for the hippocampus in contextual memory retrieval.

Key words: fear conditioning; extinction; memory retrieval; renewal; hippocampus; context; muscimol; freezing; rats

Our inactivation study suggests that the hippocampus processes the contextual retrieval cues necessary to disambiguate the conflicting CS-unconditional stimulus (US) and CS-"no event" memories formed in LI. However, an important question is whether the hippocampus is required for memory retrieval in other interference paradigms, such as extinction. In extinction, conditional responding that has been extinguished outside the conditioning context is reestablished when the CS is once again presented in the conditioning context or in a novel context (Bouton and Bolles, 1979). Insofar as the $\mathrm{DH}$ has a general role in contextual memory retrieval (Hirsh, 1974; Maren and Holt, 2000), our previous results (Holt and Maren, 1999) predict a role for the hippocampus in the contextual retrieval of fear memories after extinction.

Two recent studies suggest, however, that the hippocampus is not necessary for the context-specific expression of extinguished fear (Wilson et al., 1995; Frohardt et al., 2000). In both studies, permanent hippocampal (or fornix) lesions were made before behavioral training and testing. Rats with pretraining hippocampal lesions may adapt other neural systems to the task of contextual retrieval or adopt strategies based on unimodal cues in the context (Maren et al., 1997). Therefore, it is critical to use reversible lesions to isolate the role of the hippocampus in contextual memory retrieval after extinction. To this end, we first demonstrated the context specificity of extinction using freezing behavior as a measure of fear in rats. We then showed that inactivation of the $\mathrm{DH}$ with muscimol disrupts the contextspecific expression of extinction of conditional fear, without affecting the performance of the freezing response. The results of these experiments extend the findings of Holt and Maren (1999) and suggest a general role for the hippocampus in contextual retrieval of fear memories. 


\section{MATERIALS AND METHODS}

\section{Experiment 1}

Subjects. The subjects were 24 adult male Long-Evans rats (200-224 gm) obtained from a commercial supplier (Harlan Sprague Dawley, Indianapolis, IN). After arrival, the rats were housed individually in stainless steel hanging cages on a 14/10 hr light/dark cycle (lights on at 7:00 A.M.) and were allowed access to food ad libitum. After being housed, the rats were handled $(10-20 \mathrm{sec}$ per rat per day) for $5 \mathrm{~d}$ to habituate them to the experimenter.

Behavioral apparatus. Eight identical observation chambers $(30 \times 24 \times$ $21 \mathrm{~cm}$; Med Associates Inc., Burlington, VT) were used in the conditioning phase as "context A." The chambers were constructed from aluminum (side walls) and Plexiglas (rear wall, ceiling, and hinged front door) and were situated in sound-attenuating cabinets located in a brightly lit and isolated room. The floor of each chamber consisted of 19 stainless steel rods (4 $\mathrm{mm}$ in diameter) spaced $1.5 \mathrm{~cm}$ apart (center-tocenter). Rods were wired to a shock source and solid-state grid scrambler (Med Associates Inc.) for the delivery of footshock USs. A speaker mounted outside a grating in one wall of the chamber was used for the delivery of acoustic CSs. A $15 \mathrm{~W}$ house light was mounted on the opposite wall. The chambers were cleaned with a $5 \%$ ammonium hydroxide solution, and stainless steel pans containing a thin film of the same solution were placed underneath the grid floors before the rats were placed inside to provide a distinct odor. Ventilation fans in each chest supplied background noise ( $65 \mathrm{~dB}$, A scale).

Procedure. Rats were submitted to three phases of training: fear conditioning, extinction, and retrieval testing. For fear conditioning, rats were transported in squads of eight and placed in the conditioning chambers; chamber position was counterbalanced for each squad. The rats received five tone $(10 \mathrm{sec} ; 80 \mathrm{~dB} ; 5 \mathrm{kHz})$-footshock $(1 \mathrm{sec} ; 1 \mathrm{~mA})$ trials ( $70 \mathrm{sec}$ intertrial interval) beginning $3 \mathrm{~min}$ after being placed in the chambers. Sixty seconds after the final shock, the rats were returned to their home cages.

Twenty-four hours after the conditioning session, rats were assigned to three groups ( $n=8$ per group) that were either extinguished to the tone $(10 \mathrm{sec} ; 80 \mathrm{~dB} ; 5 \mathrm{kHz})$ in the training context (context A; SAME group) or in a novel context ("context B," see below; DIFF group), or received no tone extinction (NoEXT). Context B consisted of the same chambers used for context $\mathrm{A}$; however, the room lights and chamber houselights were turned off (a pair of $40 \mathrm{~W}$ red lights provided illumination). In addition, the doors on the sound-attenuating cabinets were closed, the ventilation fans were turned off, and the chambers were cleaned with a $1 \%$ acetic acid solution. To provide a distinct odor, stainless steel pans containing a thin film of this solution were placed underneath the grid floors before the rats were placed inside. The extinction phase lasted $5 \mathrm{~d}$. On each extinction day, each rat spent $38 \mathrm{~min}$ in both context $\mathrm{A}$ and context $\mathrm{B}$; the order of the context exposure was counterbalanced. In the extinction context, rats received 30 tone CS presentations $(10 \mathrm{sec} ; 80 \mathrm{~dB}$; $5 \mathrm{kHz} ; 60 \mathrm{sec}$ interstimulus interval) $3 \mathrm{~min}$ after placement in the context, whereas in the other context, rats received no tone presentations; rats in the NoEXT group received no tone presentations in either context. Approximately 3-4 hr elapsed between placement in the two contexts each day.

Twenty-four hours after the final extinction session, all rats were returned to context A for retrieval testing. For this test, the tone CS was presented continuously for $8 \mathrm{~min}$; tone onset occurred $2 \mathrm{~min}$ after the rats were placed in the chambers. Note that the test context (context A) was the same as the extinction context for one group of rats (SAME) but different from the extinction context for another group of rats (DIFF).

Fear to the tone CS during the extinction and testing phases was assessed by measuring freezing behavior (Maren, 1998). Each conditioning chamber rested on a load-cell platform that that was used to record chamber displacement in response to the motor activity of each rat. To ensure interchamber reliability, we calibrated each load-cell amplifier to a fixed chamber displacement. The output of the load cell of each chamber was set to a gain (vernier dial, 8) that was optimized to detect freezing behavior. Load-cell amplifier output $(-10$ to $+10 \mathrm{~V})$ from each chamber was digitized and acquired on-line using Threshold Activity software (Med Associates Inc.). Absolute values of the load-cell voltages were computed. These values were multiplied by 10 to yield a load-cell activity scale that ranged from 0 to 100 .

For each chamber, load-cell activity was digitized at $5 \mathrm{~Hz}$, yielding one observation per rat every $200 \mathrm{msec}$ (300 observations per rat per minute). In all experiments, freezing was quantified by computing the number of observations for each rat that had a value less than the freezing threshold (load-cell activity, 5; animals exhibit freezing when load-cell activity is at or below this value). To avoid counting momentary inactivity as freezing, we scored an observation as freezing only if it fell within a contiguous group of at least five observations that were all less than the freezing threshold. Thus, freezing was only scored if the rat was immobile for at least $1 \mathrm{sec}$. For each session, the freezing observations were transformed to a percentage of total observations.

Data analysis. For each session, the freezing data were transformed to a percentage of the total observations, a probability estimate that is amenable to analysis with parametric statistics. These probability estimates of freezing were analyzed using ANOVA. Post hoc comparisons in the form of Fisher's PLSD tests were performed after a significant omnibus $F$ ratio. All data are represented as means \pm SEMs.

\section{Experiment 2}

Subjects. The subjects were 32 adult male Long-Evans rats (200-224 gm) obtained and housed as described in experiment 1.

Surgery. One week before behavioral testing, rats were implanted with stainless steel guide cannulas aimed at the DH. Rats were treated with atropine methyl nitrate $(\sim 0.03 \mathrm{mg} / \mathrm{kg}$, i.p. $)$, anesthetized with sodium pentobarbital (Nembutal; $65 \mathrm{mg} / \mathrm{kg}$, i.p.), and mounted in a Kopf stereotaxic apparatus (Kopf Instruments, Tujunga, CA). The scalp was incised and retracted, and the head was positioned to place bregma and lambda in the same horizontal plane. Small holes were drilled through the skull for bilateral placement of stainless steel guide cannulas (23 gauge; $10 \mathrm{~mm}$ in length; Small Parts Inc., Miami Lakes, FL) into the DH (3.8 $\mathrm{mm}$ posterior to bregma, $2.5 \mathrm{~mm}$ lateral to bregma, $2.5 \mathrm{~mm}$ ventral to bregma) and placement of three jeweler's screws. Cannulas were affixed to the skull, and the scalp incision was closed with dental acrylic. After surgery, stainless steel obturators (30 gauge; $10 \mathrm{~mm}$ in length; Small Parts Inc.) were placed in the guide cannulas. Obturators were replaced every other day throughout the remainder of the experiment.

Behavioral apparatus. The apparatus used in this experiment was identical to that used in experiment 1 . As before, fear conditioning took place in context A. However, in this experiment, extinction and testing were conducted in two novel contexts: context B (as described in experiment 1) and context $\mathrm{C}$. Context $\mathrm{C}$ consisted of the same chambers used in experiment 1; however, all of the room lights were turned off. In addition, the ventilation fans in the sound attenuating cabinets were turned off, and the chambers were cleaned with a $100 \%$ ethanol solution. White noise was provided by a television playing static $(\sim 65 \mathrm{~dB})$. Stainless steel pans containing a thin film of the ethanol solution were placed underneath the grid floors before the rats were placed in the chambers. The only other adjustment was the addition of black Plexiglas floors $(26.5 \times 19 \mathrm{~cm})$ over the grid floors in context B.

Procedure. Rats were given 1 week after surgery for recovery and then fear-conditioned in context A as outlined in experiment 1 . Twenty-four hours after fear conditioning, rats were assigned to one of two groups $(n=16)$ that were extinguished to the tone $(10 \mathrm{sec} ; 80 \mathrm{~dB} ; 5 \mathrm{kHz})$ in either context B or context C. (Extinction context was counterbalanced in all groups.) Extinction trials proceeded as described in experiment 1, except that extinction lasted $6 \mathrm{~d}$ and $4-5 \mathrm{hr}$ elapsed between placement in the two contexts each day.

Twenty-four hours after the final extinction day, rats were transported to the room in which they would later be infused to habituate them to the infusion context. Rats were transported to the laboratory in groups of four in opaque white plastic buckets with pine shavings covering the floor of the buckets. After arrival in the infusion room, the obturators were removed from the guide cannulas of the rats, and the infusion pumps were run for $94 \mathrm{sec}$. One minute after the pumps were turned off, the obturators were replaced in the guide cannulas and the rats were returned to their home cages.

Twenty-four hours after the infusion habituation, the rats were brought back to the infusion room in squads of four in the same buckets as the previous day. The squads were completely counterbalanced for both extinction context and infusion, yielding a total of four groups in a $2 \times 2$ (extinction context $\times$ infusion) design $(n=8$ per group); the groups were called SAME-muscimol (MUS), SAME-saline (SAL), DIFF-MUS, and DIFF-SAL and were matched for levels of freezing on the last extinction day. After arrival in the infusion room, obturators were again removed from the guide cannulas. Stainless steel injection cannulas (30 gauge; $11 \mathrm{~mm}$ in length; Small Parts Inc.) connected by polyethylene tubing (PE-20; Small Parts Inc.) to $10 \mu \mathrm{l}$ syringes mounted in an infusion pump (Harvard Apparatus, South Natick, MA) were 
placed in the guide cannulas. Rats received an infusion of sterile physiological saline (0.9\%; SAL group) or muscimol $(1 \mu \mathrm{g} / \mu \mathrm{l}$ dissolved in $0.9 \%$ sterile saline; MUS group; Sigma, St. Louis, MO) at a rate of 0.32 $\mu \mathrm{l} / \mathrm{min}$ for $94 \mathrm{sec}$, resulting in a $0.5 \mu \mathrm{l}$ infusion (i.e., $0.5 \mu \mathrm{g}$ of muscimol per hemisphere). Under these conditions, muscimol inactivates brain tissue within $2 \mathrm{~mm}$ of the infusion site based on measurements of $\left[{ }^{3} \mathrm{H}\right]$ muscimol binding and 2-deoxyglucose activity (Martin, 1991). We assume, then, that our infusion procedure produces a functional inactivation of a substantial portion of the $\mathrm{DH}$. After the infusion pumps were shut off, rats remained in the buckets with the injection cannulas in place for $1 \mathrm{~min}$ to allow for diff usion of the drug. The injection cannulas were removed, and obturators were placed in the guide cannula. Rats were then returned to their home cages. After 20-25 min, the rats were brought back to the conditioning chambers for retrieval testing. Half of the animals were brought to the same context in which they had been extinguished (SAME group), whereas the other half were tested in the context that was different from the extinction context (DIFF group). Testing consisted of a continuous tone extinction test as described in experiment 1 . Freezing behavior was quantified and analyzed as described in experiment 1 .

Histology. Histological verification of cannula placements was performed after behavioral testing. Rats were perfused across the heart with physiological saline, followed by a $10 \%$ formalin solution. After extraction from the skull, brains were post-fixed in $10 \%$ formalin solution for $2 \mathrm{~d}$, at which time the solution was replaced with a $10 \%$ formalin- $-30 \%$ sucrose solution until sectioning. Sections $(40-\mu \mathrm{m}$-thick) were cut on a cryostat $\left(-19^{\circ} \mathrm{C}\right)$, wet-mounted on microscope slides, and stained with $0.25 \%$ thionin for visualization of cannula and injector tracts.

Data analysis. Freezing behavior was analyzed as described in experiment 1 . Because of technical difficulty, freezing data from the third and fifth days of extinction were not collected.

\section{Experiment 3}

Subjects. Subjects were 16 adult male Long-Evans rats (200-224 gm) obtained and housed as described in experiment 1.

Surgery and behavioral apparatus. Surgical procedures and behavioral apparatus were as described in experiment 2, except that the Plexiglas floors were removed from context $\mathrm{B}$ and placed in context $\mathrm{C}$.

Procedure. Rats were fear-conditioned in context A as described in experiment 1 . After conditioning, all rats spent $38 \mathrm{~min}$ in both of the contexts (B and C) each day for $6 \mathrm{~d}$. However, no tones were presented to any of the rats in either of the contexts. Twenty-four hours after the sixth day of context exposure, infusion habituation was performed as described in experiment 2 . On the following day, rats were assigned to one of two infusion groups ( $n=8$ per group): NoEXT-MUS and NoEXT-SAL. Infusions and testing were performed as described in experiment 2 , with half of the rats in each group tested in context $\mathrm{B}$ and the other half tested in context $\mathrm{C}$.

Histology and data analysis. Histological procedures were as described in experiment 2. Freezing behavior was analyzed as described in experiment 1.

\section{RESULTS}

\section{The expression of extinction is context-specific}

Extinction of conditional responding occurs when the CS is presented in the absence of the US after conditioning and is marked by a progressive decrement in the degree of conditional response (CR) expression. Previous studies using bar-press suppression as a measure of conditional fear have indicated that the expression of extinction is context-specific (Bouton and Bolles, 1979). Notably, conditional fear to a CS that has been extinguished outside of the conditioning context can be "renewed" when the CS is again presented in the conditioning context. In the present experiment, we sought to demonstrate the contextual specificity of extinction in this standard two-context design using freezing behavior [somatomotor immobility except for that required for respiration (Fanselow, 1980; Fendt and Fanselow, 1999)] as a measure of conditional fear. Rats were conditioned to fear an auditory CS in one context and then given CS-alone presentations (i.e., extinction) either in the same context as conditioning or in a novel context. A third group of rats did not receive CS-alone presentations. All rats were then returned to the conditioning context for a retrieval test in which a single nonreinforced CS was presented. We expected that rats extinguished outside the testing context and rats that had not received extinction trials would exhibit high levels of freezing, whereas rats extinguished in the testing context would exhibit low levels of freezing.

Freezing averaged across the first five tone trials during extinction is shown in Figure $1 A$. In all experiments, we used the data from the first five extinction trials because it served as a reliable measure of tone freezing that was not confounded by withinsession habituation. NoEXT rats did not receive tone extinction trials and are not displayed. Tone freezing declined significantly across the five extinction days $\left(F_{(4,56)}=31.3 ; p<0.0001\right)$, with no interaction between extinction context and day $\left(F_{(4,56)}=1.22\right)$, indicating that the decrease in freezing was equivalent for animals in both contexts. Twenty-four hours after the last extinction day, the rats were returned to context $\mathrm{A}$ for a retrieval test. Figure $1 B$ shows the tone freezing data during the first minute after tone onset during this test. (For all experiments, freezing during the first minute after tone onset was normalized by subtracting out the pretone freezing level of individual rats.) Freezing among the groups differed significantly during retrieval testing $\left(F_{(2,21)}=\right.$ 14.51; $p<0.0001)$. Post hoc comparisons $(p<0.05)$ indicated that rats in the SAME group froze significantly less to the tone than rats in either the DIFF or NoEXT groups, which did not differ from each other. There were no group differences in freezing during the $2 \mathrm{~min}$ before the tone onset $\left(F_{(2,21)}=2.26\right.$; data not shown). Thus, these data demonstrate that the expression of extinction is context-specific.

\section{Dorsal hippocampal inactivation blocks the context- specific expression of extinction}

Insofar as the hippocampus plays a role in the contextual retrieval of memories (Hirsh, 1974; Good and Honey, 1991; Honey and Good, 1993; Holt and Maren, 1999; Maren and Holt, 2000), it is worthwhile to study the role of the hippocampus in the contextspecific expression of extinction demonstrated in experiment 1 . Two studies using permanent hippocampal lesions before training have shown that the hippocampus does not mediate this process (Wilson et al., 1995; Frohardt et al., 2000). However, by using permanent pretraining lesions, it is impossible to isolate a role for the hippocampus in the retrieval of memories. In the present experiment, we have overcome this problem by reversibly inactivating the $\mathrm{DH}$ before retrieval testing (Holt and Maren, 1999). Muscimol, a $\mathrm{GABA}_{\mathrm{A}}$ receptor agonist, was infused into the $\mathrm{DH}$, providing us with the opportunity to isolate a temporally specific role for the hippocampus in the retrieval of fear memories after extinction.

In experiment 1 , we used the two-context design typically used to demonstrate the context-specific expression of extinction (Bouton and Bolles, 1979; Bouton and Swartzentruber, 1986; Harris et al., 2000). One problem with this design is that context-US associations acquired during training may influence the retrieval of CS-US memories during testing, which occurs in the conditioning context. Thus, in the present experiment, we used a three-context design, which allows the context specificity of extinction to be assessed outside of the conditioning context (Harris et al., 2000). Guide cannulas were surgically implanted into the DH 1 week before fear conditioning took place. After fear conditioning in one context (context $\mathrm{A}$ ), the rats were placed in two distinct contexts (contexts $\mathrm{B}$ and $\mathrm{C}$ ) during extinction training. 

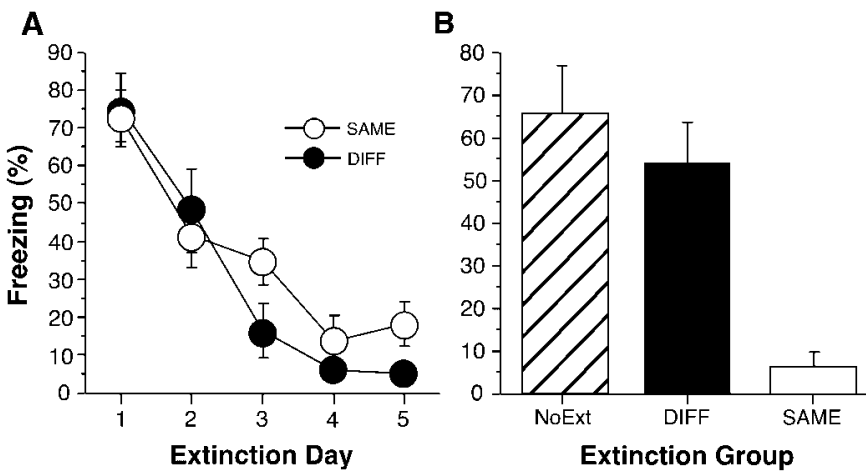

Figure 1. Context-specific expression of extinction (experiment 1). A, Mean \pm SEM percentage of freezing from the first five CS presentations across the $5 \mathrm{~d}$ of extinction in contexts A (SAME) and B (DIFF). Extinction commenced $1 \mathrm{~d}$ after fear conditioning. SAME rats (open circles) were conditioned, extinguished, and tested in context A. DIFF rats ( filled circles) were conditioned and tested in context A but extinguished in context $\mathrm{B}$. NoEXT rats (data not shown) were conditioned and tested in context A but received no extinction training. $B$, Mean $\pm \mathrm{SEM}$ percentage of freezing during the first minute after CS onset for the groups described in $A$ (SAME, open bar; DIFF, filled bar; NoEXT, striped bar).

During daily sessions, the rats received CS-alone trials in one of these contexts and equivalent exposure without CS presentation in the other context. On the testing day, the rats were tested either in the same context (SAME) as extinction or in the alternate context (DIFF) after bilateral infusions of either muscimol or saline into the $\mathrm{DH}$.

\section{Histology}

The photomicrograph in Figure 2 illustrates a representative cannula placement in the DH. Figure 3 represents the injection cannula tip placements for all rats included in the analysis. An unsuccessful infusion resulted in the removal of one rat from the analysis, thus yielding the final group sizes: SAME-SAL, $n=8$; SAME-MUS, $n=8$; DIFF-SAL, $n=8$; DIFF-MUS, $n=7$. Cannula placements were symmetrical throughout the rostrocaudal extent of the DH and did not consistently differ across groups.

Placement of the guide cannulas into the $\mathrm{DH}$ damaged some cortical tissue and caused compression of hippocampal tissue. This damage was limited to the area immediately surrounding the cannulas. The pattern of results from saline controls in this experiment (see below) did not differ from that of unoperated animals in experiment 1, suggesting that placement of the guide cannulas in the DH had no significant effect on behavior.

\section{Behavior}

Freezing averaged across the first five tone presentations during extinction is shown in Figure $4 A$. The four test groups were matched for levels of freezing on the last day of extinction, and these groups did not differ in their rates of extinction $\left(F_{(9,81)}=\right.$ 1.20). During the retrieval test after extinction, muscimol infusions into the DH did not affect the baseline levels of activity of the rats $\left(F_{(1,29)}=0.49\right)$ before tone onset (data not shown). However, muscimol infusions did influence conditional freezing during the retrieval test shown in Figure $4 B$. More specifically, hippocampal inactivation disrupted the context-specific expression of extinction; this observation was confirmed by an interaction between context and infusion $\left(F_{(1,27)}=8.14 ; p<0.01\right)$ in the ANOVA. Post hoc comparisons $(p<0.05)$ indicated that DIFFSAL rats froze significantly more than any other group, with no

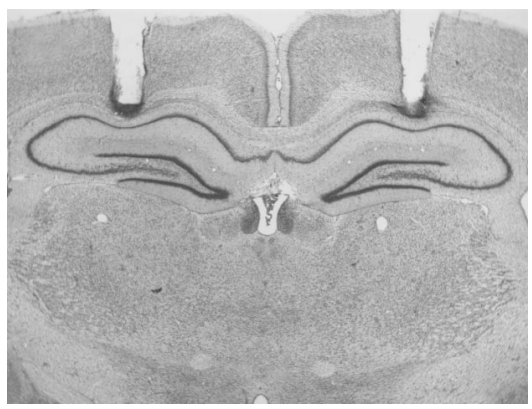

Figure 2. Cannula placement in the dorsal hippocampus (experiment 2). Photomicrograph showing a thionin-stained coronal section from the brain of a rat with representative cannula placements in the dorsal hippocampus.

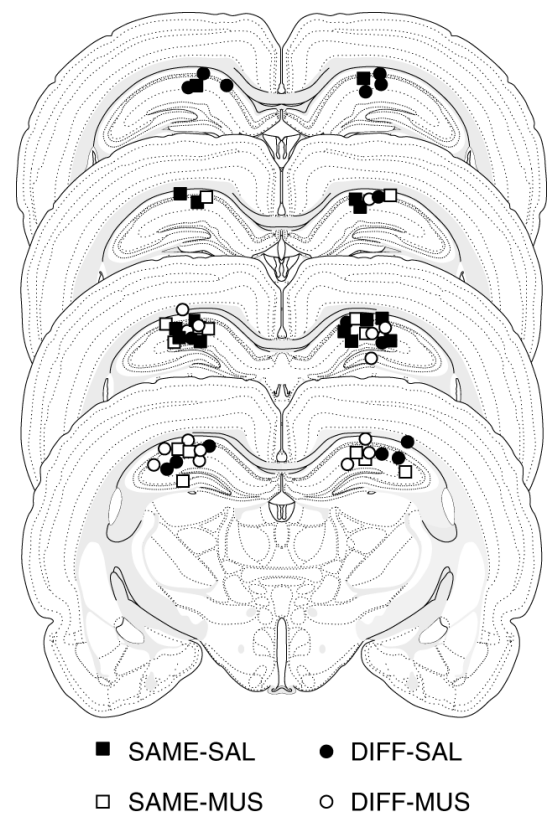

Figure 3. Illustration of injection cannula placements in the dorsal hippocampus (experiment 2). Placements represented are from all rats included in the final analysis (SAME-SAL, filled squares; SAME-MUS, open squares; DIFF-SAL, filled circles; DIFF-MUS, open circles). Atlas templates were adapted from Swanson (1992).

significant differences among the other three groups. These results reveal that the hippocampus is involved in the contextspecific expression of extinction.

\section{Dorsal hippocampal inactivation does not affect freezing performance}

In experiment 2, rats tested after infusion of muscimol into the $\mathrm{DH}$ exhibited low levels of conditional responding, regardless of the context in which testing took place. Although this finding is consistent with a role for the hippocampus in contextual retrieval of fear memories after extinction, it is possible that this result could be because of an effect of muscimol on the performance of freezing behavior. Rats with hippocampal lesions display increased motor activity (Maren et al., 1997, 1998; Richmond et al., 1999). If muscimol inf usion mimics hippocampal lesions, then the low levels of freezing observed in animals tested with muscimol in experiment 2 could simply be because of the inability of these animals to perform the freezing CR. Furthermore, muscimol may produce a general impairment in the retrieval of CS memories. 

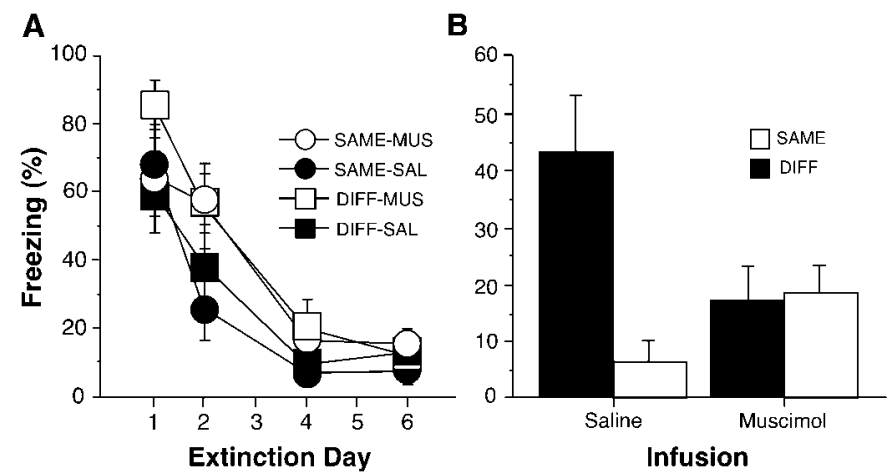

Figure 4. Muscimol infusion into the dorsal hippocampus disrupts the context-specific expression of extinction (experiment 2). A, Extinction to the CS. Mean \pm SEM percentage of freezing for the first five CS presentations across the $6 \mathrm{~d}$ of extinction in contexts B and C. Extinction commenced $1 \mathrm{~d}$ after fear conditioning and was conducted in one of two contexts (context $\mathrm{B}$ or $\mathrm{C}$ ) that were different from the conditioning context (context A). The group labels refer to the treatment conditions imposed during retrieval testing (not during extinction training). This permits an assessment of the extinction performance of each group before the retrieval test. Hence, MUS and SAL refer to infusions that were to be given before retrieval testing (no infusions were made during extinction training). Retrieval testing after extinction training was conducted either in the same context as extinction (SAME) or in a context in which the rats did not receive CS-alone presentations (DIFF). Data were not collected on days 3 and 5 of extinction because of a technical problem. $B$, Mean \pm SEM percentage of freezing during the first minute after CS onset. Rats were tested either in the same context in which extinction took place (SAME, open bars) or in a context in which no CS-alone presentations were given during the extinction phase of training (DIFF, filled bars). Retrieval testing took place $20-25$ min after an intrahippocampal infusion of either muscimol or saline.

This is a concern insofar as the low levels of freezing observed in muscimol-treated rats in experiment 2 may not reflect a contextual retrieval failure per se, but rather a general deficit in memory retrieval. We tested these possibilities in experiment 3. Rats were again trained in one context and then exposed to two novel contexts but were not given CS-alone presentations in either of these contexts. Responding to the tone CS was then measured after infusions of either muscimol or saline into the $\mathrm{DH}$ to determine whether muscimol disrupts the performance of the freeing CR.

\section{Histology}

Injection cannula tip placements are illustrated in Figure 5. As in experiment 2, cannula placements were symmetrical throughout the rostrocaudal extent of the $\mathrm{DH}$ and did not differ consistently across groups.

\section{Behavior}

Conditional freezing during the retrieval test is shown in Figure 6. Intrahippocampal muscimol infusions had no effect either on the pretone freezing levels of the rats (data not shown) or on levels of conditional freezing to the tone CS. One-way ANOVA revealed no differences in pretone activity $\left(F_{(1,14)}=1.16 ; p=0.3\right)$ or freezing during the first minute after tone onset $\left(F_{(1,14)}=\right.$ $0.057 ; p>0.8$ ) (Fig. 6) between muscimol- and saline-inf used rats during the tone extinction test. In addition to these findings, Holt and Maren (1999) demonstrated that muscimol infusions into the DH do not disrupt the ability of the rats to discriminate contexts. That is, muscimol-treated rats exhibited high levels of freezing to a context that was paired previously with shock and low levels of

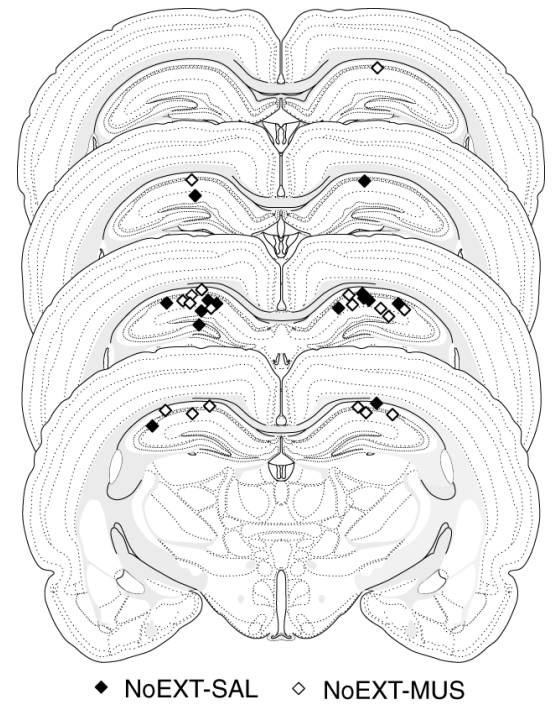

Figure 5. Illustration of injection cannula placements in the dorsal hippocampus (experiment 3). Placements represented are from all rats included in the final analysis (NoEXT-SAL, filled diamonds; NoEXTMUS, open diamonds). Atlas templates were adapted from Swanson (1992).

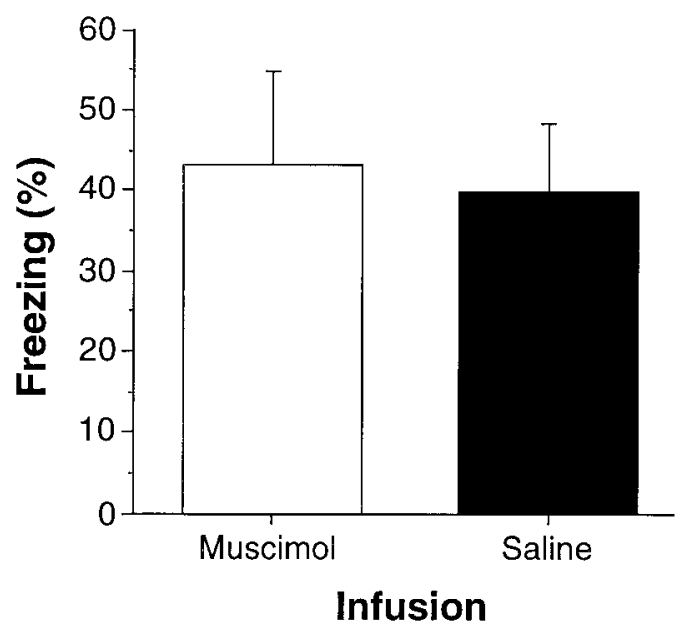

Figure 6. Muscimol infusion into the dorsal hippocampus does not disrupt the performance of freezing (experiment 3). Mean \pm SEM percentage of freezing during the first minute after tone onset during the retrieval test. The rats were tested 20-25 min after an intrahippocampal infusion of either muscimol (MUS, open bar) or saline (SAL, filled bar). The retrieval test was conducted after $5 \mathrm{~d}$ of exposure to the extinction contexts (contexts B and C) in the absence of CS-alone trials. As before, all rats received fear conditioning in context $\mathrm{A}$.

freezing to a different context that was not paired with shock. Thus, infusion of muscimol into the DH does not disrupt performance of CS-elicited freezing, the ability to discriminate contexts, or the context-independent retrieval of CS-US associations.

\section{DISCUSSION}

In the present experiments, we have used a reversible inactivation technique to examine the role of the $\mathrm{DH}$ in contextual retrieval of fear memory after extinction. Experiment 1 demonstrated that the expression of extinction is context-specific using freezing as a measure of conditional fear. In experiment 2, it was shown that the $\mathrm{DH}$ plays a vital role in the context-specific expression of 
extinguished fear memories. That is, reversible inactivation of the $\mathrm{DH}$ eliminated the elevation in conditional responding to an extinguished CS that occurs outside of the extinction context. Hippocampal inactivation had no effect on the performance of freezing or retrieval of fear memories to the tone CS in nonextinguished rats in experiment 3 . This indicates that the deficits in the context-specific expression of extinction shown in experiment 2 were because of a deficit in contextual retrieval in the rats rather than because of a disruption of the freezing response, sensory processing of the tone $\mathrm{CS}$, or memory retrieval in general. Intrahippocampal muscimol infusions did not result in locomotor hyperactivity, which is often observed in rats with hippocampal lesions (Maren and Fanselow, 1997). This is consistent with findings that rats tested for contextual fear after post-training lesions of the $\mathrm{DH}$ or hippocampal inactivation can still perform the freezing response (Maren et al., 1998; Anagnostaras et al., 1999; Holt and Maren, 1999; cf. McNish et al., 1997).

These results, together with the results from Holt and Maren (1999), suggest an important and specific role for the hippocampus in contextual memory retrieval in Pavlovian conditioning paradigms. We believe that the role of the hippocampus in contextual retrieval complements its role in contextual encoding (Maren et al., 1998; Rudy and O'Reilly, 1999; Fanselow, 2000; Anagnostaras et al., 2001). Indeed, additional work is required to determine whether the hippocampus is involved in encoding the contextual relationships that are necessary to support contextual memory retrieval. More broadly, these data are consistent with recent studies indicating a role for the hippocampus in the retrieval of spatial memory (Riedel et al., 1999), implicit contextual information (Chun and Phelps, 1999), and episodic memories (Eldridge et al., 2000).

In contrast to the present results, two recent studies have found that pretraining electrolytic lesions of the fimbria/fornix (Wilson et al., 1995) or neurotoxic hippocampal lesions (Frohardt et al., 2000) do not affect the context-specific expression of extinction in a bar-press suppression paradigm. This discrepancy may be because of differences in the nature of the hippocampal lesion, the opportunity for recovery of function in rats with permanent lesions, or the use of a nonhippocampal strategy or an extrahippocampal neural system to mediate contextual retrieval. For example, we have found differences in the effects of pretraining and post-training hippocampal lesions on contextual fear conditioning (Maren et al., 1997). Based on these results, we have argued that rats with pretraining lesions of the hippocampus condition fear to contexts using elemental (i.e., unimodal) cues in the context, whereas intact rats use a hippocampus-dependent configural strategy (Rudy and O'Reilly, 1999). In the case of contextual retrieval, it may be the case that cortical regions implicated in memory retrieval, such as the prefrontal cortex (Wagner et al., 1998), can assume the functions of the hippocampus in rats afforded the opportunity for recovery after permanent lesions.

Nonetheless, our inactivation data support a role for the $\mathrm{DH}$ in contextual memory retrieval. Holt and Maren (1999) proposed that the hippocampus is necessary for contextual retrieval cues to disambiguate CS-US and CS-no event associations in LI. Extinction and LI are similar phenomena in that contextual retrieval cues disambiguate conflicting CS memories and determine performance. Bouton (1994) has proposed a model to explain how context mediates the expression of conditional responding after extinction. According to this model, extinction results in the formation of an inhibitory association between the CS and US, which reduces conditional responding to the CS. According to Bouton, this inhibition is only expressed in the extinction context (i.e., inhibition is gated so that it occurs only with the simultaneous presence of the CS and the extinction context). Holt and Maren (1999) expanded this model, proposing that the DH is necessary to limit the expression of inhibitory CS-no event associations to the context in which they are acquired. The present results are consistent with this model and reveal a role for the DH in contextual "gating" of both CS-no event associations (as in LI) and inhibitory CS-US associations (as in extinction).

This model also fits well with Hirsh's (1974) model of memory storage and retrieval. In his associative model, performance is driven by the algebraic sum of the associations that have been made to a CS. Responding along this "performance line" is similar to most stimulus $\rightarrow$ response theories of learning and does not require the hippocampus. In Hirsh's hippocampus-dependent retrieval model, memories are "indexed" by the hippocampus according to the contextual cues present when learning takes place and stored somewhere off of the performance line. In situations in which a stimulus has more than one meaning, the hippocampus uses contextual cues to retrieve the meaning of that stimulus appropriate to the retrieval context. In the absence of a functional hippocampus, performance reverts to Hirsh's performance line; in the case of experiment 2, $180 \mathrm{CS}-$ no event presentations outweigh five CS-US pairings, resulting in low levels of freezing among rats with inactivated hippocampi.

Similarly, context may be acting as an "occasion setter" in interference paradigms, such as LI and extinction (Bouton and Swartzentruber, 1986). For example, in negative occasion setting, a "feature" stimulus precedes a "target" stimulus on trials when the US does not follow the target. In situations in which a CS has accrued multiple meanings (e.g., the CS-US and CS-no event associations in LI and extinction), it has been argued that the retrieval context acts as the feature or occasion-setter for the selective retrieval of the appropriate meaning of the target CS (Bouton, 1993). In these cases, the extinction or preexposure contexts may serve as negative occasion setters, insofar as they predict the absence of the US. Interestingly, a selective role for the hippocampus in negative occasion setting has been reported recently (Holland et al., 1999). Of course, there may also be a role for positive occasion setting in these paradigms. For example, in the two-context design used in experiment 1 , the conditioning context may serve as a positive occasion setter to facilitate retrieval of the excitatory memory of an extinguished CS (i.e., renewal). The role for the hippocampus in this process is unclear (Ross et al., 1984; Jarrard and Davidson, 1991; Holland et al., 1999). Unfortunately, our data do not allow us to address the role of the hippocampus in positive occasion setting, because we did not examine the impact of hippocampal inactivation on conditional responding to an extinguished CS in the conditioning context.

In a broader theoretical framework, our data are completely consistent with a role for the hippocampus in declarative memory (Squire and Zola, 1996). For example, Eichenbaum and Cohen (1993) have suggested that relational associations and the flexible expression of these associations characterize declarative memory. Indeed, in our extinction paradigm, performance is contingent upon the flexible expression of CS-US and CS-“no US" associations, which, as we have shown, rely on hippocampus-dependent contextual memory retrieval (Holt and Maren, 1999). It has been argued that representational flexibility permits the use of knowledge in novel contexts, a type of context-independent retrieval 
(Eichenbaum and Cohen, 1993). We would add that representational flexibility also supports the context-specific expression of memory by allowing contexts to index and gate the multiple meanings that a stimulus has acquired. In humans, the role of the hippocampus in contextual memory (Chun and Phelps, 1999) and the retrieval of declarative memories (Eldridge et al., 2000) has recently been supported. This represents convergent validity across different behavioral paradigms and species for a hippocampal role in contextual memory retrieval.

In conclusion, we have demonstrated that the hippocampus is involved in contextual memory retrieval after extinction in a Pavlovian fear-conditioning paradigm in rats. Use of a reversible inactivation technique allowed us to isolate the role of the hippocampus in memory retrieval with a degree of temporal resolution that is impossible with permanent lesions (Lorenzini et al., 1996; Holt and Maren, 1999; Riedel et al., 1999). Together with the results of Holt and Maren (1999), we have now demonstrated a role for the hippocampus in the context-dependent retrieval of fear memories in two Pavlovian interference paradigms (Bouton, 1993). Additional studies are required to understand the generality of hippocampal involvement in contextual retrieval in other behavioral paradigms.

\section{REFERENCES}

Anagnostaras SG, Maren S, Fanselow MS (1999) Temporally graded retrograde amnesia of contextual fear after hippocampal damage in rats: within-subjects examination. J Neurosci 19:1106-1114.

Anagnostaras SG, Gale GD, Fanselow MS (2001) The hippocampus and contextual fear conditioning: recent controversies and advances. Hippocampus, in press.

Bouton ME (1993) Context, time, and memory retrieval in the interference paradigms of Pavlovian conditioning. Psychol Bull 114:80-99.

Bouton ME (1994) Context, ambiguity, and classical conditioning. Curr Dir Psychol Sci 3:1-5.

Bouton ME, Bolles RC (1979) Contextual control of the extinction of conditioned fear. Learn Motiv 10:445-466.

Bouton ME, Swartzentruber D (1986) Analysis of the associative and occasion-setting properties of contexts participating in a Pavlovian discrimination. J Exp Psychol Anim Behav Process 12:333-350.

Chun MM, Phelps EA (1999) Memory deficits for implicit contextual information in amnesic subjects with hippocampal damage. Nat Neurosci 2:844-847.

Eichenbaum H, Cohen NJ (1993) Memory, amnesia, and the hippocampal system. Cambridge, MA: MIT.

Eldridge LL, Knowlton BJ, Furmanski CS, Bookheimer SY, Engel SA (2000) Remembering episodes: a selective role for the hippocampus during retrieval. Nat Neurosci 3:1149-1152.

Fanselow MS (1980) Conditional and unconditional components of postshock freezing. Pavlov J Biol Sci 15:177-182.

Fanselow MS (2000) Contextual fear, gestalt memories, and the hippocampus. Behav Brain Res 110:73-81.

Fendt M, Fanselow MS (1999) The neuroanatomical and neurochemical basis of conditioned fear. Neurosci Biobehav Rev 23:743-760.

Frohardt RJ, Guarraci FA, Bouton ME (2000) The effects of neurotoxic hippocampal lesions on two effects of context after fear extinction. Behav Neurosci 114:227-240.

Good M, Honey RC (1991) Conditioning and contextual retrieval in hippocampal rats. Behav Neurosci 105:499-509.

Harris JA, Jones ML, Bailey GK, Westbrook RF (2000) Contextual control over conditioned responding in an extinction paradigm. J Exp Psychol Anim Behav Process 26:174-185.

Hirsh R (1974) The hippocampus and contextual retrieval of information from memory: a theory. Behav Biol 12:421-444.

Holland PC, Bouton ME (1999) Hippocampus and context in classical conditioning. Curr Opin Neurobiol 9:195-202.
Holland PC, Lamoureux JA, Han JS, Gallagher M (1999) Hippocampal lesions interfere with Pavlovian negative occasion setting. Hippocampus 9:143-157.

Holt W, Maren S (1999) Muscimol inactivation of the dorsal hippocampus impairs contextual retrieval of fear memory. J Neurosci 19:9054-9062.

Honey RC, Good M (1993) Selective hippocampal lesions abolish the contextual specificity of latent inhibition and conditioning. Behav Neurosci 107:23-33.

Jarrard LE, Davidson TL (1991) On the hippocampus and learned conditional responding: effects of aspiration vs. ibotenate lesions. Hippocampus 1:103-113.

Lorenzini CA, Baldi E, Bucherelli C, Sacchetti B, Tassoni G (1996) Role of dorsal hippocampus in acquisition, consolidation, and retrieval of rat's passive avoidance response: a tetrodotoxin functional inactivation study. Brain Res 730:32-39.

Maguire EA, Frackowiak RSJ, Frith CD (1997) Recalling routes around London: activation of the right hippocampus in taxi drivers. J Neurosci 17:7103-7110.

Maren S (1998) Overtraining does not mitigate contextual fear conditioning deficits produced by neurotoxic lesions of the basolateral amygdala. J Neurosci 18:3088-3097.

Maren S, Fanselow MS (1997) Electrolytic lesions of the fimbria/fornix, dorsal hippocampus, or entorhinal cortex produce anterograde deficits in contextual fear conditioning in rats. Neurobiol Learn Mem 67:142-149.

Maren S, Holt W (2000) The hippocampus and contextual memory retrieval in Pavlovian conditioning. Behav Brain Res 110:97-108.

Maren S, Aharonov G, Fanselow MS (1997) Neurotoxic lesions of the dorsal hippocampus and Pavlovian fear conditioning in rats. Behav Brain Res 88:261-274.

Maren S, Anagnostaras SG, Fanselow MS (1998) The startled seahorse: is the hippocampus necessary for contextual fear conditioning? Trends Cogn Sci 2:39-42.

Martin JH (1991) Autoradiographic estimation of the extent of reversible inactivation produced by microinjection of lidocaine and muscimol in the rat. Neurosci Lett 127:160-164.

McNish KA, Gewirtz JC, Davis M (1997) Evidence of contextual fear after lesions of the hippocampus: a disruption of freezing but not fear-potentiated startle. J Neurosci 17:9353-9360.

Richmond MA, Pouzet B, Veenman L, Feldon J, Yee BK, Rawlins JNP, Bannerman DM (1999) Dissociating context and space within the hippocampus: effects of complete of complete, dorsal, and ventral excitotoxic hippocampal lesions on conditioned freezing and spatial learning. Behav Neurosci 113:1189-1203.

Riedel G, Micheau J, Lam AGM, Roloff EL, Martin SJ, Bridge H, de Hoz L, Poeschel B, McCulloch J, Morris RGM (1999) Reversible neural inactivation reveals hippocampal participation in several memory processes. Nat Neurosci 2:898-905.

Ross RT, Orr WB, Holland PC, Berger TW (1984) Hippocampectomy disrupts acquisition and retention of learned conditional responding. Behav Neurosci 98:211-225.

Rudy JW, O'Reilly RC (1999) Contextual fear conditioning, conjunctive representations, pattern completion, and the hippocampus. Behav Neurosci 113:867-880.

Spear NE (1973) Retrieval of memory in animals. Psychol Rev 80:163-194.

Squire LR, Zola SM (1996) Structure and function of declarative and nondeclarative memory systems. Proc Natl Acad Sci USA 93:13515-13522.

Swanson LW (1992) Brain maps: structure of the rat brain. New York: Elsevier.

Tulving E, Thomson DM (1973) Encoding specificity and retrieval processes in episodic memory. Psychol Rev 80:352-373.

Wagner AD, Desmond JE, Glover GH, Gabrieli JD (1998) Prefrontal cortex and recognition memory: functional-MRI evidence for contextdependent retrieval processes. Brain 121:1985-2002.

Westbrook RF, Jones ML, Bailey GK, Harris JA (2000) Contextual control over conditioned responding in a latent inhibition paradigm. J Exp Psychol Anim Behav Process 26:157-173.

Wilson A, Brooks DC, Bouton ME (1995) The role of the rat hippocampal system in several effects of context in extinction. Behav Neurosci 109:828-836. 